\title{
Fatty acid ester metabolites of gymnodimine in shellfish collected from China and in mussels (Mytilus galloprovincialis) exposed to Karenia selliformis
}

\author{
Ji Ying 1, 2, Che Yijia 1,2, Wright Elliott J. ${ }^{3}$, McCarron Pearse ${ }^{3}$, Hess Philipp ${ }^{4}$, Li Aifeng 1, 2, *
}

${ }^{1}$ College of Environmental Science and Engineering, Ocean University of China, Qingdao 266100, China

2 Key Laboratory of Marine Environment and Ecology, Ocean University of China, Ministry of Education, Qingdao 266100, China

${ }^{3}$ Biotoxin Metrology, National Research Council Canada, 1411 Oxford Street, Halifax, Nova Scotia B3H 3Z1, Canada

4 Ifremer, Phycotoxins Laboratory, Nantes, France

* Corresponding author : Aifeng Li, email address : lafouc@ouc.edu.cn

\begin{abstract}
:
Marine shellfish exposed to the microalgae Karenia selliformis can accumulate gymnodimines (GYM). Shellfish samples collected from Beihai City in Guangxi Autonomous Region, and Ningde City in Fujian Province, in the South China Sea, as well as mussels Mytilus galloprovincialis fed on K. selliformis under laboratory conditions were analyzed. Gymnodimines and various fatty acid ester metabolites were detected in the clam Antigona lamellaris and pen shell Atrina pectinata, while no esters were found in the oyster Crassostrea sp. and the gastropod Batillaria zonalis despite positive detection of free GYM in both species. When present, the predominant acyl esters observed were 18:0-GYM-A and 20:1-GYM-A. Under laboratory conditions GYM-A was accumulated and metabolized to fatty acid esters in mussels exposed to K. selliformis, with 16:0-GYM-A and 20:1-GYM-A as the major variants. A novel compound with the same accurate mass as GYM-A and its 16:0 fatty acid ester were observed in the experimental mussels but was not present in the microalgal strain to which mussels were exposed. No significant differences of reactive oxygen species (ROS) levels and antioxidant enzymes were found between mussels fed on K. selliformis or GYM-free microalgae Isochrysis galbana. This suggests the accumulation of GYM and its metabolites does not significantly impact the physiological status of mussels. While it is currently not proven that GYM affects human health, risk assessments should consider the presence of GYM esters in naturally contaminated shellfish as part of exposure analysis.
\end{abstract}




\section{Graphical abstract}

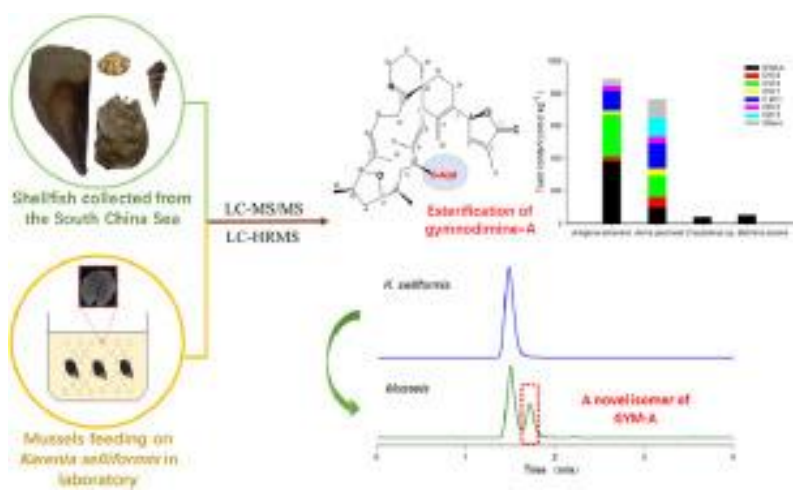

\section{Highlights}

GYM-A was detected in four species of field marine mollusks from Chinese coast. Diverse fatty acid esters of GYM-A were found in clam and pen shell, but not in oyster and gastropod. GYM-A and its different fatty acid esters accumulated in mussels fed with Karenia selliformis. The esters 16:0-GYMA and 20:1-GYM-A were the major components in the experimental mussels. A novel compound with the same accurate mass as GYM-A and its esters were also observed in mussels.

Keywords : Gymnodimines (GYM), Fatty acid ester, Karenia selliformis, Toxin profiles, Antioxidant enzymes 


\section{Introduction}

Marine bivalves have the capacity to accumulate phycotoxins produced by harmful algae and generate a diverse range of secondary metabolites, collectively known as shellfish toxins (Salas and Clarke, 2019). These toxins can be divided into eight groups, including saxitoxins, azaspiracids, brevetoxins, cyclic imines, domoic acids, okadaic acids, pectenotoxins, and yessotoxins (Toyofuku, 2006). Gymnodimines (GYM) (Fig. 1) are a group of fast-acting cyclic imine toxins initially identified in oysters collected in New Zealand (Seki et al., 1995; Stewart et al., 1997). GYM-A, GYM-B and GYM-C are produced by the dinoflagellate Karenia selliformis (Miles et al., 2000, 2003; Seki et al., 1995). 12-methyl-gymnodimine was subsequently verified as natural product in the dinoflagellate Alexandrium ostenfeldii from estuaries on the U.S. East Coast (Van Wagoner et al., 2011) and the Netherlands (Van de Waal et al., 2015). Additionally, A. ostenfeldii from the northern Baltic Sea was shown to produce a new analogue, GYM-D (Harju et al., 2016). Gymnodimines have also been documented in shellfish from coastal regions of Tunisia (Biré et al., 2002; Marrouchi et al., 2010), Australia (Takahashi et al., 2007), Europe \& North America (Kharrat et al., 2008), South Africa (Krock et al., 2009) and China (Jiang et al., 2017; Li et al., 2015; Liu et al., 2011a). A recent study demonstrated that fatty acid ester metabolites of GYMA constitute the majority ( $>90 \%$ ) of GYM toxins present in clam samples (Ruditapes decussatus) from Tunisia (de la Iglesia et al., 2013). Several unknown GYM-like compounds have been detected in shellfish (McCarron et al., 2014) and in A. ostenfeldii by liquid chromatography-mass spectrometry (LC-MS) (Harju et al., 2016; Qiu et al., 2018). Considering the high intraperitoneal toxicity (LD $\mathrm{L}_{50}$ of $80-96 \mathrm{mg} \mathrm{kg}^{-1}$ ) of GYMA to mice, and albeit lower relative oral toxicity (Munday et al., 2004), these metabolites should be considered when evaluating the risks of GYMs in shellfish for human consumption.

Antioxidant enzyme activity in bivalves is influenced by reactive oxygen species (ROS) and may be an indication of organism health and oxidative stress (Box et al., 2007; Fernández et al., 2012; Gillis et al., 2014; Hu et al., 2015a; Regoli and Principato, 
1995). Antioxidant responses are enhanced when the production of ROS increases, resulting in oxidative stress (Hu et al., 2015b; Pan et al., 2006). The antioxidant and immune systems of shellfish, including superoxide dismutase (SOD), catalase (CAT), glutathione peroxidase (GSH-Px), glutathione reductase (GR), glutathione (GSH) and lysozyme (LZM), are responsible for eliminating ROS and foreign particles. Paralytic shellfish toxins accumulated from toxic microalgae induced oxidative stress in mussels (Mytilus galloprovincialis) and scallops (Patinopecten yessoensis), where ROS were reduced by antioxidant enzymes under laboratory conditions (Qiu et al., 2013).

The objective of this work was to analyze the profiles of GYM and its fatty acid esters in various species of shellfish relevant to the coastal regions of China, with a specific focus on the South China Sea. Laboratory studies were conducted on mussels (M. galloprovincialis) fed with the GYM-producing microalgae $K$. selliformis to study the uptake and metabolism of GYM-A, and to monitor the response of antioxidant enzymes (SOD, CAT, GSH).

\section{Materials and Methods}

\subsection{Reagents}

Ammonium formate and formic acid were from Fisher Scientific (Fair Lawn, NJ, USA) or Honeywell-Fluka (Oakville, ON, Canada). Acetonitrile, methanol, monopotassium phosphate $\left(\mathrm{KH}_{2} \mathrm{PO}_{4}\right)$ and disodium hydrogen phosphate $\left(\mathrm{Na}_{2} \mathrm{HPO}_{4}\right)$ were from Merck Ltd. (White-house Station, NJ, USA). A certified reference material (CRM) of GYM-A was obtained from the National Research Council of Canada (Halifax, NS, Canada). Milli-Q water was supplied by a Milli-Q water purification system from Millipore Ltd. (Bedford, MA, USA) to $18.2 \mathrm{M} \Omega$ quality or better.

\subsection{Culture of microalgae and sample preparation}

$K$. selliformis (strain GM94GAB) used in the feeding experiment was isolated from the Gulf of Gabes, Tunisia (Medhioub et al., 2009). The strain was maintained in sterilized seawater filtered with $0.45 \mu \mathrm{m}$ mixed fiber membrane (Jinjing Ltd., China) in photo-bioreactors $(120 \mathrm{~L})$ without aeration. The culture was enriched with $\mathrm{f} / 2$ medium without silicate (Guillard and Ryther, 1962) at $18 \pm 2^{\circ} \mathrm{C}$ under 6000 lx light intensity 
with a $12 \mathrm{~h}$ : $12 \mathrm{~h}$ illumination cycle. Algal cells were counted by optical microscopy at a magnification of 100 on a Sedgewick Rafter Counting Chamber and collected at the stable growth stage to feed mussels.

Isochrysis galbana 3011 kept at Ocean University of China was used as a control diet in the feeding experiment. The culture conditions of I. galbana were as above for K. selliformis, without aeration. The batch of I. galbana was collected when the algal density approached $10^{8}$ cells $\mathrm{mL}^{-1}$.

A freeze-dried pellet $\left(2.6 \times 10^{6}\right.$ cells $)$ of the cultured $K$. selliformis was extracted using a 1/16" microtip ultrasonicator probe with coupler (QSonica LLC (CT, USA) in $1 \mathrm{~mL}$ methanol using a cycle with $40 \%$ amplitude pulse mode for a total of $3 \mathrm{~min}$. The sample was held in an ice bath to prevent the solution from heating during extraction. The sample was then filtered using a $0.45 \mu \mathrm{m}$ PVDF centrifugal filter (Merck Millipore Ltd.) prior to LC-MS analysis.

\subsection{Shellfish samples}

Multiple species of commercially grown shellfish were collected at shellfish harvesting regions in the South China Sea in March 2016. This included clams (Antigona lamellaris), pen shells (Atrina pectinata) and oysters (Crassostrea sp.) from Beihai City, Guangxi Autonomous Region, and gastropod (Batillaria zonalis) from Ningde City, Fujian Province. Whole tissue samples ( $\sim 1 \mathrm{~g})$ were weighed and extracted with $3 \mathrm{~mL}$ methanol on an ice using a superfine homogenizer (F6/10, Fluko) at speeds ranging from 5000 to $32000 \mathrm{rpm}$ in three $30 \mathrm{~s}$ cycles. The supernatant was carefully transferred to a $10 \mathrm{~mL}$ volumetric flask after centrifugation $\left(2400 \times g\right.$ for $10 \mathrm{~min}$ at $\left.4^{\circ} \mathrm{C}\right)$. The remaining pellet was re-extracted twice more as above and the combined supernatants were adjusted to a final volume of $10 \mathrm{~mL}$ and passed through $0.22 \mu \mathrm{m}$ polyamide nylon filters into HPLC vials and stored at $-20^{\circ} \mathrm{C}$ until LC-MS analysis.

\subsection{Feeding experiment and sample preparation}

Mussels (M. galloprovincialis) were obtained from a marine aquaculture zone along the coast of Qingdao, China, in October 2016. They were transported alive to the laboratory and washed to remove epibionts. Mussels were randomly divided into two 
tanks $(60 \mathrm{~L})$ and acclimated in filtered seawater with continuous aeration at $16 \pm 2{ }^{\circ} \mathrm{C}$ for 3 days. During this period, seawater (without any feed) was renewed twice daily at 08:00 and 20:00.

After acclimation, mussels in the first tank (treatment group) were fed with $K$. selliformis for four days and then starved for three days. They were maintained in a $60 \mathrm{~L}$ tank with fresh seawater containing the toxic microalgae at an initial density of 1000 cells $\mathrm{mL}^{-1}$. The $K$. selliformis culture and fresh seawater were continuously supplied for four days using a peristaltic pump to maintain the initial algal density. The volume of seawater in the tank was kept constant. Fresh seawater alone was added for the three days of starvation. Acclimated mussels in the second tank were used as a blank control. Experimental settings for the control group were the same as for the treatment group, with the exception of the diet. The non-toxic microalga I. galbana was pumped and maintained at a density of 10000 cells $\mathrm{mL}^{-1}$ for the first four days. Both tanks were continuously aerated during the entire experiment. Mussels $(n=10)$ were selected randomly and dissected at various time points (0, 12, 24, 48, 72, 96, 120, 144, and 168 h). The muscle (containing foot and adductor muscle) and digestive gland of mussels were separated. Tissue samples $(1 \pm 0.1 \mathrm{~g})$ of both treatment groups were prepared as described in section 2.3 .

For ROS determinations, tissue samples $(0.5 \mathrm{~g})$ were homogenized in $10 \mathrm{~mL}$ phosphate buffer $(0.1 \mathrm{M}, \mathrm{pH}=7.0)$ containing $2.6 \mathrm{mM} \mathrm{KH}_{2} \mathrm{PO}_{4}$ and $4.1 \mathrm{mM} \mathrm{Na}_{2} \mathrm{HPO}_{4}$ for 3 mins on an ice-water bath. The supernatant from centrifugation $\left(2400 \times g, 4^{\circ} \mathrm{C}, 20\right.$ min) was collected. To analyze activity of antioxidant enzymes (CAT, SOD, GSH) additional tissue samples $(1 \pm 0.1 \mathrm{~g})$ were homogenized and centrifuged in $9 \mathrm{~mL}$ physiological saline $(0.9 \%)$ following the conditions as described above. The supernatant was collected.

\subsection{LC-MS analysis for GYM and esters}

The LC-MS method was modified from a previous study (Li et al., 2016). An HPLC (Agilent 1290, Palo Alta, CA, USA) was coupled with a triple quadrupole mass spectrometer (Agilent 6430, Palo Alta, CA, USA) equipped with an ESI interface. A 
172 Luna $\mathrm{C}_{18}$ column $(50 \times 2.1 \mathrm{~mm}$ i.d., $3 \mu \mathrm{m}$, Phenomenex $)$ was used at $35^{\circ} \mathrm{C}$. Mobile

173 phases A (water) and B (95\% acetonitrile) contained with $50 \mathrm{mM}$ formic acid and 2 $174 \mathrm{mM}$ ammonium formate. A gradient at $300 \mu \mathrm{L} \mathrm{min}^{-1}$ was run from $25 \%$ to $100 \% \mathrm{~B}$ over

$1757 \mathrm{~min}$, held for $3 \mathrm{~min}$ and returned to $25 \% \mathrm{~B}$ over $1 \mathrm{~min}$ before re-equilibration for 3 176 min. Injection volume was set at $5 \mu \mathrm{L}$. Selected reaction monitoring (SRM) transitions 177 for all the acyl ester derivatives of GYM-A were described previously (de la Iglesia et 178 al., 2013). Product ion $m / z$ 490.3, fragmentor energy $150 \mathrm{~V}$, collision energy $30 \mathrm{~V}$, and 179 dwell time $15 \mathrm{~ms}$ were used to scan fatty acid esters of GYM-A. Concentrations of 180 GYM and metabolites of GYM-A were roughly estimated using CRM-GYM-A as a 181 reference material assuming equal molar responses.

\subsection{LC-HRMS analysis for GYM and esters}

An HPLC (Agilent 1200, Palo Alto, CA, USA), was coupled with high resolution mass spectrometer (Q-Exactive HF, Thermo Fisher Scientific, Bremen, Germany) equipped with a heated electrospray ionization probe (HESI-II). A Luna $\mathrm{C}_{18}$ column (50 $\times 2 \mathrm{~mm}$ i.d., $2.5 \mu \mathrm{m}$, Phenomenex) was used with mobile phase, flow rate, and temperature the same as described in section 2.5. The gradient ran from $15 \%$ to $100 \%$ $\mathrm{B}$ over $10 \mathrm{~min}$, held for $15 \mathrm{~min}$, and then returned to $15 \% \mathrm{~B}$ over $0.1 \mathrm{~min}$ before reequilibration for $7 \mathrm{~min}$. Injection volumes were $1 \mu \mathrm{L}$. Mobile phase was diverted to waste for the first 1.5 minutes of the run. Source conditions were spray voltage 3000, capillary temperature $350^{\circ} \mathrm{C}$, sheath gas and auxillary gas at 35 and 10 (arbitrary units) respectively with heat set to $300^{\circ} \mathrm{C}$, and S-Lens RF Level at 50. Full scan data was acquired in positive mode from $\mathrm{m} / \mathrm{z} 400-900$ using the $60 \mathrm{k}$ resolution setting with an automatic gain control (AGC) target $1 \mathrm{e} 6$ ions, 100 ms maximum injection time. MS/MS spectra were collected through 'TopN' experiments. These TopN experiments used data-dependent acquisition with the top 10 most intense ions (not on an exclusion list of background ions) selected for fragmentation from the full scan survey, with preferential fragmentation given to ions above an intensity threshold of $1.6 \mathrm{e} 5$ ions from an inclusion list of known GYM and acyl ester variants. Apex trigger was set from 2-6 $\mathrm{s}$ with dynamic exclusion for $4 \mathrm{~s}$ in efforts to capture spectra near the apex of the 
chromatographic peak. Spectra were collected at the $15 \mathrm{k}$ resolution setting, $50 \mathrm{~ms}$ maximum injection time, an isolation window of $1 \mathrm{~m} / \mathrm{z}$ about the parent mass with a collision energy spread of 30, $65 \mathrm{eV}$. Focused collection of free GYM spectra was done using parallel reaction monitoring (PRM) mode at the $30 \mathrm{k}$ resolution setting, 2e5 AGC target, $100 \mathrm{~ms}$ maximum injection time, isolation window $0.4 \mathrm{~m} / \mathrm{z}$, and collision energy spread set at $40,75 \mathrm{eV}$.

\subsection{Analysis of antioxidant enzymes}

The level of ROS and activities of antioxidant enzymes (SOD, CAT, GSH) in the digestive gland and muscle of mussels from both groups were analyzed using test kits for antioxidant enzyme biomarkers acquired from Nanjing Jiancheng Bioengineering Institute Ltd. (Nanjing, China) as described by (Liu, et al., 2011b; Ji et al., 2018a). The measuring principles are in accordance with specifications in kits.

\section{Results}

\subsection{Profiles of GYM and esters in field shellfish collected from China}

Varying concentrations of GYM-A was present in the four shellfish species tested. Concentrations of GYM-A as well as the relative molar percentages of predominant acyl esters in field mollusk samples are shown in Table 1. Acyl esters of GYM-A were found in the clam (Antigona lamellaris) and the pen shell (Atrina pectinata), while no fatty acid esters were found in the oyster (Crassostrea sp.) and the gastropod (Batillaria zonalis). The profile of GYM-A acyl esters observed varied between clams and pen shell samples. Octadecanoic acid (18:0) ester was the most abundant (50\%), followed by the eicosenoic acid (20:1) (23\%) in the clam. While 20:1-GYM ester (23\%), 18:0GYM ester (20\%), and the docosadienoic acid (22:2) (18\%) ester dominated the profile in the pen shell sample. The extent of GYM-A esterification was estimated for clam and pen shell samples assuming equimolar response for the esters against GYM-A standard, and were approximately $58 \%$ and $87 \%$ respectively.

\subsection{GYM and esters in mussels from feeding experiment}

LC-MS/MS SRM chromatograms for esters of GYM-A in digestive gland tissue of 
mussels (M. galloprovincialis) fed with K. selliformis after $96 \mathrm{~h}$ are shown in Fig. 2. Twenty-eight fatty acid esters (odd- and even-chains) were identified in the experimental mussels. The K. selliformis used as feed microalga for mussels in this study primarily produces only free GYM-A and a trace amount of GYM-B (Fig. S1A). The mussels were free of GYM toxins before feeding on K. selliformis (Fig. S1C and D). LC-HRMS full scan chromatograms for GYM-A CRM, 16:0 GYM-A positive control tissue which was previously confirmed in using synthetic 16:0 GYM-A (Iglesia et al., 2013), K. selliformis culture and experimental mussels are shown in Fig. 3. Product-ion spectra (MS/MS) (Fig. 4) of GYM-A in the extract of digestive gland sample (treatment group-96 h), were acquired to confirm the accumulation and esterification of GYM-A in mussels fed with K. selliformis in laboratory. An additional GYM peak (4.66 min), not present in the microalgae, was also observed in the shellfish with the same measured accurate mass as GYM (Fig. 3 and 4). This new GYM analogue also formed esters (14.84 min) in the mussels (Fig. 3).

The concentrations of GYM-A and the relative amounts of acyl ester metabolites varied in the muscle and digestive gland tissues of mussels (Fig. 5). The acyl esters accounted for an estimated $98 \%$ of the GYM total in the muscle and digestive glands. Toxin concentrations increased during the algae-feeding period and stabilized during the starvation period. The highest concentration in the muscle tissues was at $120 \mathrm{~h}$ and $96 \mathrm{~h}$ for the digestive gland tissues. The sum concentration of GYM and GYM esters reached a maximum of $\sim 760 \mathrm{nmol} \mathrm{kg}-1$ in the muscle tissues, while it was four times higher in the digestive gland samples. The relative proportion of GYM-A and the major ester metabolites (16:0, 18:0, 18:1, 20:1, 20:2, 22:2) differed in both tissues (Fig. 5). In the muscle samples, the relative abundance of 16:0-GYM-A was dominant (33\%) in the first $48 \mathrm{~h}$ but gradually declined to $14 \%$, while the relative abundance of $20: 1$ GYM-A increased from $12 \%$ to $34 \%$, and reached the highest level among ester metabolites after $48 \mathrm{~h}$. The relative proportions of acyl esters in the digestive gland samples was consistent over the duration of the experiment with 16:0-GYM-A constituting approximately $30 \%$ esters detected.

Molar concentrations of GYM-A in the muscle and digestive gland tissues are 
shown in Fig. S2A. The esters 22:2-GYM-A, 20:1-GYM-A, 18:0-GYM-A and 16:0GYM-A were most abundant for their respective carbon chain lengths (Fig. S2B-E). The nutritionally important $\omega$-3-fatty acids, EPA (C20:5) and DHA (C22:6) abundant in mussels (Fernández-Reiriz et al., 1996), formed much less acyl esters compared to the four derivatives above. Trends of each metabolite over time in these four groups were similar to the variations of GYM-A in the digestive gland tissues.

\subsection{Responses of Antioxidant System}

The ROS levels from the control and treatment groups followed similar trends (Fig. S3). ROS levels reduced slightly when feeding on toxic or non-toxic microalgae at 12 $\mathrm{h}$, and did not change significantly until $144 \mathrm{~h}$. Variations of CAT activity, SOD activity and GSH level in muscle and digestive glands are also shown in Fig. S3. These enzyme activity levels exhibited similar trends, showing minor fluctuation without significant changes over the course of the study.

\section{Discussion}

Accumulation of marine phycotoxins in shellfish is an important seafood safety issue due to frequent occurrence of toxic algal blooms in coastal areas worldwide (James et al., 2010). To properly assess the toxicity of shellfish exposed to harmful algal species, esterification of lipophilic toxins such as okadaic acid, pectenotoxins, spirolides and pinnatoxins has been studied (JØrgensen et al., 2005; Aasen et al., 2006; McCarron et al., 2012). The occurrence of GYM esters in shellfish highlights the need for methods to quantitate total profiles of GYM. Gymnodimines degrade under alkaline hydrolysis conditions and the enzymatic hydrolysis method still needs modification to be applied to cyclic imines (de la Iglesia et al., 2013; Doucet et al., 2007). Currently direct analysis of acyl esters by LC-MS is the most practical option for GYM ester measurement, however this is limited by availability of standards for GYM esters. In this work, individual ester concentrations were estimated assuming equal response of the esters and GYM-A. While total GYM esters measured were significant, these numbers can only be considered indicative. Monitoring lipophilic toxins in cultured mussels (Mytilus coruscus) during a previous study (Li et al., 2015) showed low 
amounts of GYM-A are common throughout the year in the mariculture zone of Gouqi Island in the East China Sea. A subsequent study on lipophilic shellfish toxins showed higher concentrations of GYM-A were frequently detected in shellfish collected from the South China Sea (Ji et al., 2018b). GYM-A was present in the four field mollusk samples tested here. GYM-B, an analog of GYM-A, was first isolated and elucidated from K. selliformis (Miles et al., 2000). No GYM-B was detected in field samples. Trace amounts of GYM-B were present in the K. selliformis, and both the experimental mussels and seawater collected at $96 \mathrm{~h}$ during the feeding experiment (Fig. S1 A and B). A positive detection of GYM-B in clams also occurred in a previous study (Naila et al., 2012).

Acyl ester metabolites have been observed for a variety of marine phycotoxins in a range of shellfish species (Comesaña Losada et al., 1999; García et al., 2004; JØrgensen et al., 2005; Torgersen et al., 2008a; 2008b; Wilkins et al., 2006). Based on previous reports of acyl ester metabolites for other classes of cyclic imines including spirolides (Aasen et al., 2006) and pinnatoxins (McCarron et al., 2012), and because of the previous study showing GYM esters in Tunisian clams (Ruditapes decussatus) (de al Iglesia et al., 2013), the presence of GYM esters in Chinese shellfish is not unexpected. In this study, concentration and profile of ester metabolites varied in clam (Antigona lamellaris) and pen shell (Atrina pectinata) samples, but weren't detected in oyster (Crassostrea sp.) or gastropod (B. zonalis) samples (Table 1), indicating that GYM esterification in mollusks may be species-specific. Possibly some key enzymes govern the metabolism of GYM esters in shellfish. The species specific profiles observed in GYM esterification should be studied further.

The feeding experiment demonstrated the acylation process under controlled laboratory conditions. GYM-A and GYM derived esters analyzed in this work showed parent masses $<5 \mathrm{ppm}$, and 490-fragment masses $<3.5 \mathrm{ppm}$. The 392-fragment observed for GYM-A and its esters, was not present for GYM-like species ( $m / z 508)$ (Fig. 4). Various ester metabolites were confirmed in the experimental mussels based on characterized transitions and relative retention times of esters published before (Fig. 2). The high relative abundance (90\%-98\%) of esterified GYM at each sampling-time 
point (Fig. 5), including the first time point at $12 \mathrm{~h}$, indicates that these Phase-II metabolites of GYM-A are formed very rapidly and that esterification constitutes a major metabolic process for these toxins. Relatively static distribution of acyl esters and GYM-A in digestive gland samples indicates GYM-A and its metabolites are readily retained in shellfish, possibly explaining the persistence of GYM-A in oysters (Seki et al., 1995) and clams (Naila et al., 2012). Considering the relative abundance of different GYM-A esters in the digestive gland tissue, percentages of free GYM-A and 16:0 ester slightly decreased in the depuration period after $96 \mathrm{~h}$, which demonstrated that they were excreted or transformed faster than 20:1 ester, 22:2 ester, and 18:0 ester. This tendency is also observed for GYM-A and the 16:0 ester in muscle tissue in the depuration period (data not shown).

It is interesting to note that the unidentified GYM analog observed in the mussels after feeding, with the same accurate mass as GYM-A, also formed ester metabolites (Fig. 3 and 4). The origin of this GYM analog was not confirmed in this study, but it was not observed in direct analysis of the toxin-producing K. selliformis by LC-HRMS. The typical GYM-A product ions $m / z 392$ and 446 were absent in the MS/MS spectra of this new compound (Fig. 4), indicating a possible structural variation between C1-4 (Fig. 1). This compound may have been a product of metabolism in the mussels, or may be an artefact from sample preparation or processing. LC-HRMS experiments did not reveal the presence of any other significant GYM related compounds in the microalgae (data not shown). The formation of this compound will be considered in further studies.

All mussels were alive during the feeding experiment. Similar to the response of scallops (Chlamys farreri) and mussels (M. galloprovincialis) exposed to azaspiracids in our previous study (Ji et al., 2018), no significant difference of ROS levels and antioxidant enzymes were found in mussels exposed to the GYM-producing microalgae. This indicates there is no measurable impact of GYM accumulation on the antioxidant enzyme system of mussels based on this study.

\section{Conclusions}

GYM-A and ester metabolites were confirmed in the clam (Antigona lamellaris) 
and pen shell (Atrina pectinata) samples collected from the South China Sea and in experimental mussels (M. galloprovincialis) fed with K. selliformis under laboratory conditions. While GYM-A was detected in the oyster (Crassostrea sp.) and gastropod (B. zonalis) samples, no GYM-A esters were detected. Various acyl esters were detected by SRM analysis and the predominant esters were confirmed by LC-HRMS. Esterification and ester profiles appear to be species-specific for mollusks. In mussels, ester metabolites constituted the majority of total GYMs $(>90 \%$ for laboratory fed samples), with the 18:0-GYM-A and 20:1-GYM-A formed as the most abundant ester derivatives in the field samples analyzed. K. selliformis feeding demonstrated no toxic effects on mussels based on responses of antioxidant enzymes. A novel GYM analogue with the same accurate mass as GYM-A, which also formed fatty acid ester, was found in the experimental mussels. Risks posed by GYMs and their acyl esters should be assessed in future toxicological studies and risk assessments.

\section{Conflict of interest}

All authors declare that there are no conflicts of interest.

\section{Acknowledgement}

This work was funded by the National Natural Science Foundation of China (41876112) and the Fundamental Research Funds for the Central Universities (201841003). The authors are grateful for the support of Florent Malo (Ifremer) for the provision of cell pellets of cultures of $K$. selliformis. 


\section{References:}

Aasen, J.A.B., Hardstaff, W., Aune, T., Quilliam, M.A. (2006). Discovery of fatty acid ester metabolites of spirolide toxins in mussels from Norway using liquid chromatography/tandem mass spectrometry. Rapid Communications in Mass Spectrometry, 20(10), 1531-1537. doi: $10.1002 / \mathrm{rcm} .2501$

Biré, R., Krys, S., Frémy, J.M, Dragacci, S., Stirling, D., Kharrat, R. (2002). First evidence on occurrence of gymnodimine in clams from Tunisia. Journal of Nature Toxins, 4(11), 269-275

Blanco, J., Mariño, C., Martín, H., Acosta, C.P. (2007). Anatomical distribution of diarrhetic shellfish poisoning (DSP) toxins in the mussel Mytilus galloprovincialis. Toxicon, 50(8), 10111018. doi: 10.1016/j.toxicon.2007.09.002

Box, A., Sureda, A., Galgani, F., Pons, A., Deudero, S. (2007). Assessment of environmental pollution at Balearic Islands applying oxidative stress biomarkers in the mussel Mytilus galloprovincialis. Comparative Biochemistry and Physiology Part C: Toxicology \& Pharmacology, 146(4), 531-539. doi: 10.1016/j.cbpc.2007.06.006

Comesaña Losada, M., Leão, J.M., Gago-Martínez, A., Rodríguez Vázquez, J.A., Quilliam, M.A. (1999). Further Studies on the Analysis of DSP Toxin Profiles in Galician Mussels. Journal of Agricultural and Food Chemistry, 47(2), 618-621. doi: 10.1021/jf971043a

de la Iglesia, P., McCarron, P., Diogène, J., Quilliam, M.A. (2013). Discovery of gymnodimine fatty acid ester metabolites in shellfish using liquid chromatography/mass spectrometry. Rapid Communications in Mass Spectrometry, 27(5), 643-653. doi: 10.1002/rcm.6491

Doucet, E., Ross, N.N., Quilliam, M.A. (2007). Enzymatic hydrolysis of esterified diarrhetic shellfish poisoning toxins and pectenotoxins. Analytical and Bioanalytical Chemistry, 389(1), 335-342. doi: 10.1007/s00216-007-1489-3

Fernández, B., Campillo, J.A., Martínez-Gómez, C., Benedicto, J. (2012). Assessment of the mechanisms of detoxification of chemical compounds and antioxidant enzymes in the digestive gland of mussels, Mytilus galloprovincialis, from Mediterranean coastal sites. Chemosphere, 87(11), 1235-1245. doi: 10.1016/j.chemosphere.2012.01.024

Fernández-Reiriz, M.J., Labarta, U., Babarro, J.M.F. (1996). Comparative allometries in growth and chemical composition of mussel (Mytilus galloprovincialis Lmk) cultured in two zones in the Ria sada (Galicia, NW Spain). Journal of Shellfish Research, 15, 349-353. http://hdl.handle.net/10261/61211

García, C., González, V., Cornejo, C., Palma-Fleming, H., Lagos, N. (2004). First evidence of Dinophysistoxin-1 ester and carcinogenic polycyclic aromatic hydrocarbons in smoked bivalves collected in the Patagonia fjords. Toxicon, 43(2), 121-131. doi: 10.1016/j.toxicon.2003.10.028

Gillis, P.L., Higgins, S.K., Jorge, M.B. (2014). Evidence of oxidative stress in wild freshwater mussels (Lasmigona costata) exposed to urban-derived contaminants. Ecotoxicology and Environmental Safety, 102, 62-69. doi: 10.1016/j.ecoenv.2013.12.026

Guillard, R.R., Ryther, J.H. (1962). Studies of marine planktonic diatoms: I. Cyclotella Nana 
Hustedt, and Detonula Confervacea (CLEVE) Gran. Canadian Journal of Microbiology, 8(2), 229-239. doi: 10.1139/m62-029

Harju, K., Koskela, H., Kremp, A., Suikkanen, S., de la Iglesia, P., Miles, C.O., Krock, B., Vanninen, P. (2016). Identification of gymnodimine D and presence of gymnodimine variants in the dinoflagellate Alexandrium ostenfeldii from the Baltic Sea. Toxicon, 112, 68-76. doi: 10.1016/j.toxicon.2016.01.064

Hu, M., Li, L., Sui, Y., Li, J., Wang, Y., Lu, W., Dupont, S. (2015b). Effect of pH and temperature on antioxidant responses of the thick shell mussel Mytilus coruscus. Fish \& Shellfish Immunology, 46(2), 573-583. doi: 10.1016/j.fsi.2015.07.025

Hu, M., Wu, F., Yuan, M., Li, Q., Gu, Y., Wang, Y., Liu, Q. (2015a). Antioxidant responses of triangle sail mussel Hyriopsis cumingii exposed to harmful algae Microcystis aeruginosa and hypoxia. Chemosphere, 139, 541-549. doi: 10.1016/j.chemosphere.2015.07.074

James, K.J., Carey, B., O'Halloran J., van Pelt F.N.A.M., Škrabáková Z. (2010). Shellfish toxicity: human health implications of marine algal toxins. Epidemiology \& Infection, 138(7), 927-940. doi: $10.1017 / \mathrm{S} 0950268810000853$

Ji, Y., Hu, Y., Song, J.L., Chen, H.D., Li, A.F. (2018b). Characteristics of components and regional distribution of lipophilic shellfish toxins in bivalves cultured along the Chinese coast in Spring. Chinese Fishery Quality and Standards, 8(4), 15-24. (in Chinese)

Ji, Y., Qiu, J., Xie, T., McCarron, P., Li, A. (2018a). Accumulation and transformation of azaspiracids in scallops (Chlamys farreri) and mussels (Mytilus galloprovincialis) fed with Azadinium poporum, and response of antioxidant enzymes. Toxicon, 143, 20-28. doi: 10.1016/j.toxicon.2017.12.040

Jiang, T., Liu, L., Li, Y., Zhang, J., Tan, Z., Wu, H., Jiang, T., Lu, S. (2017). Occurrence of marine algal toxins in oyster and phytoplankton samples in Daya Bay, South China Sea. Chemosphere, 183, 80-88. doi: 10.1016/j.chemosphere.2017.05.067

JØrgensen, K., Scanlon, S., Jensen, L.B. (2005). Diarrhetic shellfish poisoning toxin esters in Danish blue mussels and surf clams. Food Additives and Contaminants, 22(8), 743-751. doi: $10.1080 / 02652030500136928$

Kharrat, R., Servent, D., Girard, E., Ouanounou, G., Amar, M., Marrouchi, R., Benoit, E., Molgó, J. (2008). The marine phycotoxin gymnodimine targets muscular and neuronal nicotinic acetylcholine receptor subtypes with high affinity. Journal of Neurochemistry. doi: 10.1111/j.1471-4159.2008.05677.x

Krock, B., Pitcher, G., Ntuli, J., Cembella, A. (2009). Confirmed identification of gymnodimine in oysters from the west coast of South Africa by liquid chromatography - tandem mass spectrometry, 31(1), 113-118. doi: 10.2989/AJMS.2009.31.1.12.783

Li, A., Jiang, B., Chen, H., Gu, H. (2016). Growth and toxin production of Azadinium poporum strains in batch cultures under different nutrient conditions. Ecotoxicology and Environmental Safety, 127, 117-126. doi: 10.1016/j.ecoenv.2016.01.017 
Li, A., Sun, G., Qiu, J., Fan, L. (2015). Lipophilic shellfish toxins in Dinophysis caudata picked cells and in shellfish from the East China Sea. Environmental Science and Pollution Research, 22(4), 3116-3126. doi: 10.1007/s11356-014-3595-z

Liu, R., Liang, Y., Wu, X., Xu, D., Liu, Y., Liu, L. (2011a). First report on the detection of pectenotoxin groups in Chinese shellfish by LC-MS/MS. Toxicon, 57(7-8), 1000-1007. doi: 10.1016/j.toxicon.2011.04.002

Liu, X., Xi, Q., Yang, L., Li, H., Jiang, Q., Shu, G., Wang, S., Gao, P., Zhu, X., Zhang, Y. (2011b). The effect of dietary Panax ginseng polysaccharide extract on the immune responses in white shrimp, Litopenaeus vannamei. Fish \& Shellfish Immunology, 30(2), 495-500. doi: 10.1016/j.fsi.2010.11.018

Marrouchi, R., Dziri, F., Belayouni, N., Hamza, A., Benoit, E., Molgó, J., Kharrat, R. (2010). Quantitative Determination of Gymnodimine-A by High Performance Liquid Chromatography in Contaminated Clams from Tunisia Coastline. Marine Biotechnology, 12(5), 579-585. doi: 10.1007/s10126-009-9245-7

McCarron, P., Rourke, W.A., Hardstaff, W., Pooley, B., Quilliam, M.A. (2012). Identification of Pinnatoxins and Discovery of Their Fatty Acid Ester Metabolites in Mussels (Mytilus edulis) from Eastern Canada. Journal of Agricultural and Food Chemistry, 60(6), 1437-1446. doi: $10.1021 / \mathrm{jf} 204824 \mathrm{~s}$

McCarron, P., Wright, E., Quilliam, M.A. (2014). Liquid Chromatography/Mass Spectrometry of Domoic Acid and Lipophilic Shellfish Toxins with Selected Reaction Monitoring and Optional Confirmation by Library Searching of Product Ion Spectra. Journal of AOAC International, 97(2), 316-324. doi: 10.5740/jaoacint.SGEMcCarron

Medhioub, A., Medhioub, W., Amzil, Z., Sibat, M., Bardouil, M., Ben Neila, I., Mezghani, S., Hamza, A., Lassus, P. (2009). Influence of environmental parameters on Karenia selliformis toxin content in culture. CBM - Cahiers de Biologie Marine, 50(4), 333-342

Miles, C.O., Wilkins, A.L., Stirling, D.J., MacKenzie, A.L. (2000). New Analogue of Gymnodimine from a Gymnodinium Species. Journal of Agricultural and Food Chemistry, 48(4), 1373-1376. doi: $10.1021 /$ jf991031k

Miles, C.O., Wilkins, A.L., Stirling, D.J., MacKenzie, A.L. (2003). Gymnodimine C, an Isomer of Gymnodimine B, from Karenia selliformis. Journal of Agricultural and Food Chemistry, 51(16), 4838-4840. doi: 10.1021/jf030101r

Munday, R., Towers, N.R., Mackenzie, L., Beuzenberg, V., Holland, P.T., Miles, C.O. (2004). Acute toxicity of gymnodimine to mice. Toxicon, 44(2), 173-178. doi: 10.1016/j.toxicon.2004.05.017

Naila, I.B., Hamza, A., Gdoura, R., Diogène, J., de la Iglesia, P. (2012). Prevalence and persistence of gymnodimines in clams from the Gulf of Gabes (Tunisia) studied by mouse bioassay and LCMS/MS. Harmful Algae, 18, 56-64. doi: 10.1016/j.hal.2012.04.004

Pan, L.Q., Ren, J., Liu, J. (2006). Responses of antioxidant systems and LPO level to benzo(a)pyrene and benzo(k)fluoranthene in the haemolymph of the scallop Chlamys ferrari. 
Qiu J., Rafuse C., Lewis N.I., Li A., Meng F., Beach D.G., McCarron P. (2018) Screening of cyclic imine and paralytic shellfish toxins in isolates of the genus Alexandrium (Dinophyceae) from Atlantic Canada. Harmful Algae, 77, 108-118.

Qiu, J., Ma, F., Fan, H., Li, A. (2013). Effects of feeding Alexandrium tamarense, a paralytic shellfish toxin producer, on antioxidant enzymes in scallops (Patinopecten yessoensis) and mussels (Mytilus galloprovincialis). Aquaculture, 396-399, 76-81. doi: 10.1016/j.aquaculture.2013.02.040

Regoli, F., Principato, G. (1995). Glutathione, glutathione-dependent and antioxidant enzymes in mussel, Mytilus galloprovincialis, exposed to metals under field and laboratory conditions: implications for the use of biochemical biomarkers. Aquatic Toxicology, 31(2), 143-164. doi: 10.1016/0166-445X(94)00064-W

Salas R., and Clarke D. (2019). Review of DSP toxicity in Ireland: Long-term trend impacts, biodiversity and toxin profiles from a monitoring perspective. Toxins, 11(61), 1-19. doi:10.3390/toxins11020061

Seki, T., Satake, M., Mackenzie, L., Kaspar, H.F., Yasumoto, T. (1995). Gymnodimine, a New Marine Toxin of Unprecedented Structure Isolated from New Zealand Oysters and the Dinoflagellate, Gymnodinium sp. Tetrahedron Letters, 36(39), 7093-7096. doi: 10.1016/00404039(95)01434-J

Stewart, M., Blunt, J.W., Munro, M.H.G., Robinson, W.T., Hannah, D.J. (1997). The absolute stereochemistry of the New Zealand shellfish toxin gymnodimine. Tetrahedron Letters, 38(27), 4889-4890. doi: 10.1016/S0040-4039(97)01050-2

Takahashi, E., Yu, Q., Eaglesham, G., Connell, D.W., McBroom, J., Costanzo, S., Shaw, G.R. (2007). Occurrence and seasonal variations of algal toxins in water, phytoplankton and shellfish from North Stradbroke Island, Queensland, Australia. Marine Environmental Research, 64(4), 429-442. doi: 10.1016/j.marenvres.2007.03.005

Torgersen, T., Lindegarth, S., Ungfors, A., Sandvik, M. (2008a). Profiles and levels of fatty acid esters of okadaic acid group toxins and pectenotoxins during toxin depuration, Part I: Brown crab (Cancer pagurus). Toxicon, 52(3), 407-417. doi: 10.1016/j.toxicon.2008.06.010

Torgersen, T., Sandvik, M., Lundve, B., Lindegarth, S. (2008b). Profiles and levels of fatty acid esters of okadaic acid group toxins and pectenotoxins during toxin depuration. Part II: Blue mussels (Mytilus edulis) and flat oyster (Ostrea edulis). Toxicon, 52(3), 418-427. doi: 10.1016/j.toxicon.2008.06.011

Toyofuku, H. (2006). Joint FAO/WHO/IOC activities to provide scientific advice on marine biotoxins (research report). Marine Pollution Bulletin, 52(12), 1735-1745. doi: 10.1016/j.marpolbul.2006.07.007

Van de Waal, D.B., Tillmann, U., Martens, H., Krock, B., van Scheppingen, Y., John, U. (2015). Characterization of multiple isolates from an Alexandrium ostenfeldii bloom in The Netherlands. Harmful Algae, 49, 94-104. doi: 10.1016/j.hal.2015.08.002 
Van Wagoner, R.M., Misner, I., Tomas, C.R., Wright, J.L.C. (2011). Occurrence of 12methylgymnodimine in a spirolide-producing dinoflagellate Alexandrium peruvianum and the biogenetic implications. Tetrahedron Letters, 52(33), 4243-4246. doi: 10.1016/j.tetlet.2011.05.137

Wilkins, A.L., Rehmann, N., Torgersen, T., Rundberget, T., Keogh, M., Petersen, D., Hess, P., Rise, F., Miles, C.O. (2006). Identification of Fatty Acid Esters of Pectenotoxin-2 Seco Acid in Blue Mussels (Mytilus edulis) from Ireland. Journal of Agricultural and Food Chemistry, 54(15), 5672-5678. doi: 10.1021/jf060396j 


\section{Tables}

Table 1. Concentrations of GYM-A (nmol/kg) and molar percentages of predominant GYM-A esters (to the sum esters in each sample) in the field samples collected from Chinese coasts.

\begin{tabular}{lcccccccc}
\hline \multirow{2}{*}{ Sample } & GYM-A & \multicolumn{4}{c}{ percentage of predominant esters (\%) } & \multicolumn{2}{c}{ ER* $^{*}$} \\
& $(\mathbf{n m o l} / \mathbf{k g})$ & $\mathrm{C} 16: 0$ & $\mathrm{C} 18: 0$ & $\mathrm{C} 18: 1$ & $\mathrm{C} 20: 1$ & $\mathrm{C} 20: 2$ & $\mathrm{C} 22: 2$ & $(\%)$ \\
\hline clam (Antigono lamellaris) & 382 & 4.9 & 50 & 4.3 & 23 & 5.9 & 4.2 & 58 \\
pen shell (Atrina pectinata) & 99 & 11 & 20 & 7.6 & 23 & 7.1 & 18 & 87 \\
oyster (Crassostrea sp.) & 42 & - & - & - & - & - & - & - \\
gastropod (Batillaria zonalis) & 55 & - & - & - & - & - & - & - \\
\hline
\end{tabular}

Esters of GYM-A were estimated using GYM-A as calibration standards.

${ }^{*}$ ER means the esterification rate of GYM-A roughly estimated by GYM-A reference material; ER(\%) = esters/(esters + GYM-A) $\times 100$.

- means not detected in samples. 


\section{Legends of Figures}

Figure 1. Chemical structures of select gymnodimine analogs.

Figure 2. LC-MS/MS chromatograms for fatty acid esters of GYM-A in digestive gland tissue of mussels (M. galloprovincialis) fed with K. selliformis after $96 \mathrm{~h}$.

Figure 3. LC-HRMS full scan chromatograms for GYM-A (left) and 16:0 GYM-A (right) using a $1.5 \mathrm{ppm}$ mass tolerance, normalized to $100 \%$ intensity for $\mathrm{m} / \mathrm{z} 508.3421$ in each sample. Samples shown are NRC-CRM gymnodimine (A), NRC positive control tissue (B), microalgal feed culture (K. selliformis) (C), and muscle tissues (D) and digestive gland tissues (E) of mussels (M. galloprovincialis) after $96 \mathrm{~h}$ feeding time point of this study.

Figure 4. High resolution MS/MS spectra for GYM-A in certified reference material, and GYM-A and a second peak bearing GYM-A mass in mussel digestive gland (MDG) sample (LEFT). Spectra for 16:0 GYM-A acyl ester in positive control tissue, and the two 16:0 acyl esters derived from the GYM-A and the second GYM-like compound in MDG sample (RIGHT).

Figure 5. Fatty acid esters of GYM-A in muscle (A) and digestive gland (B) tissues of mussels (M. galloprovincialis) collected at each sampling time point. The bars show the relative distribution of GYM-A including free form, selected individual ester and other esters (total free form and esters of GYM-A =100). The lines show the sum of the relative amounts of esters to the total toxin burden in \% (filled triangle), the level of esters (filled squares) and esters + toxin (filled circles), both in $\mathrm{nmol} \mathrm{kg}^{-1}$ tissue (right hand side axis). 

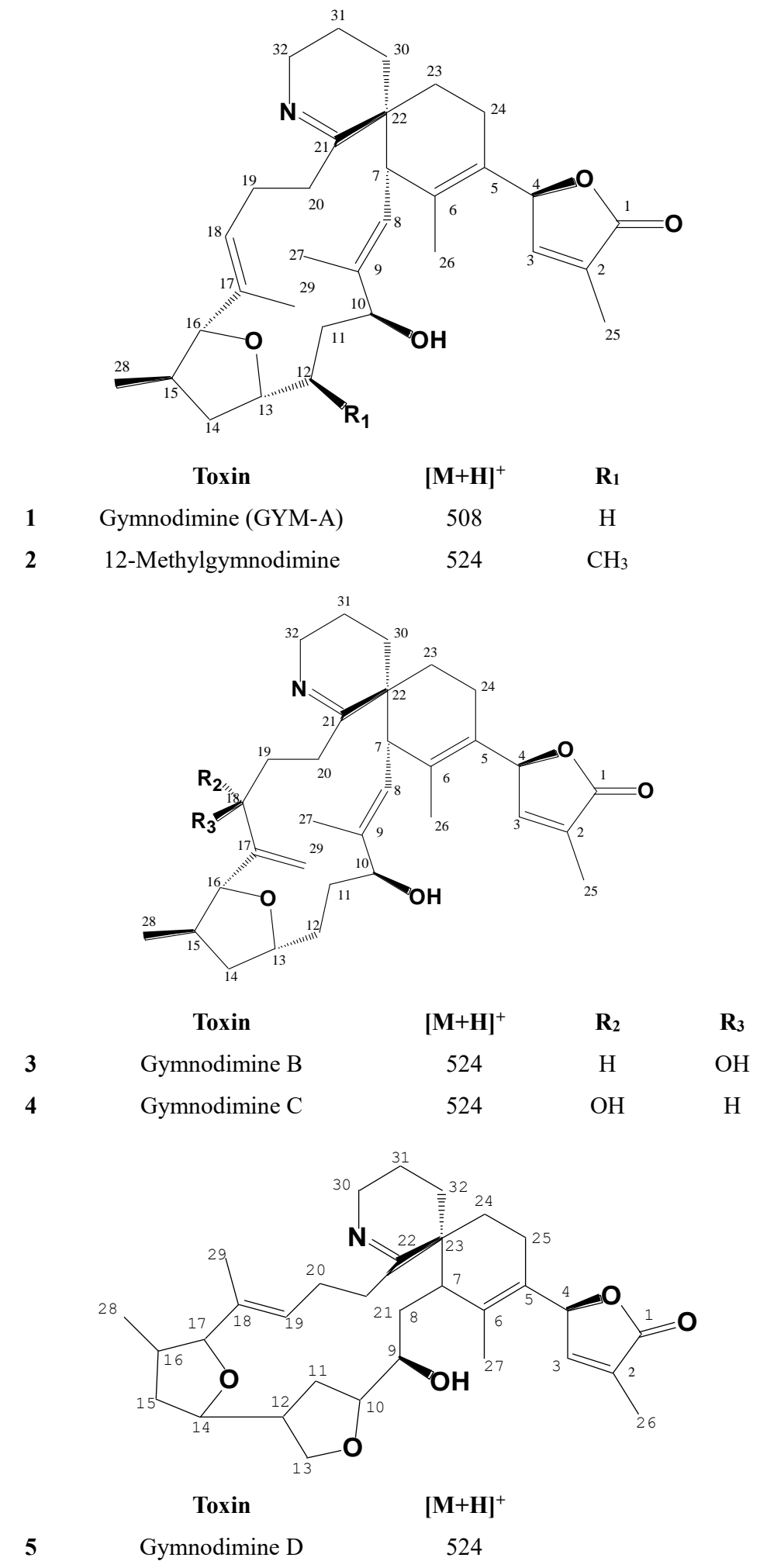

Fig. 1 


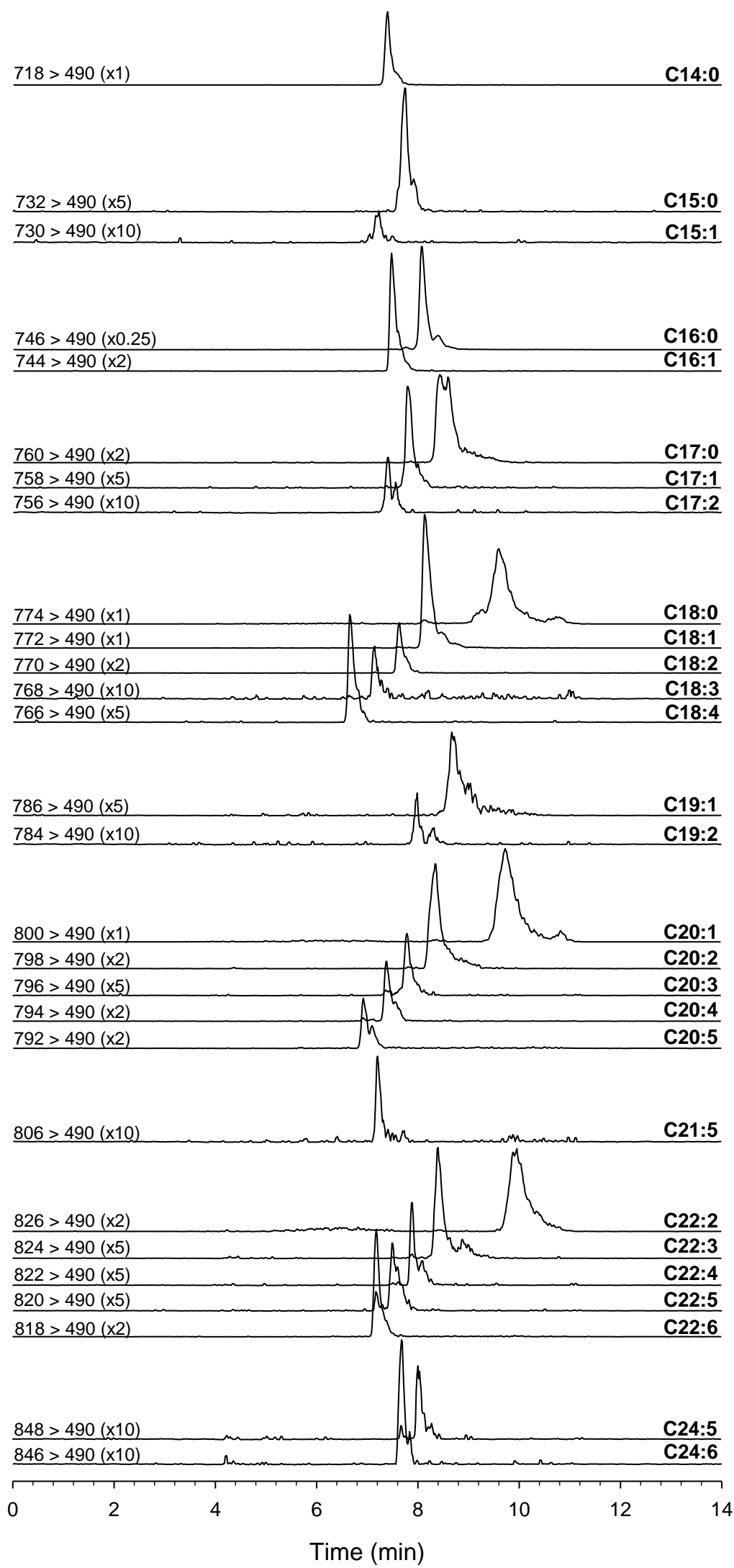

Fig.2 


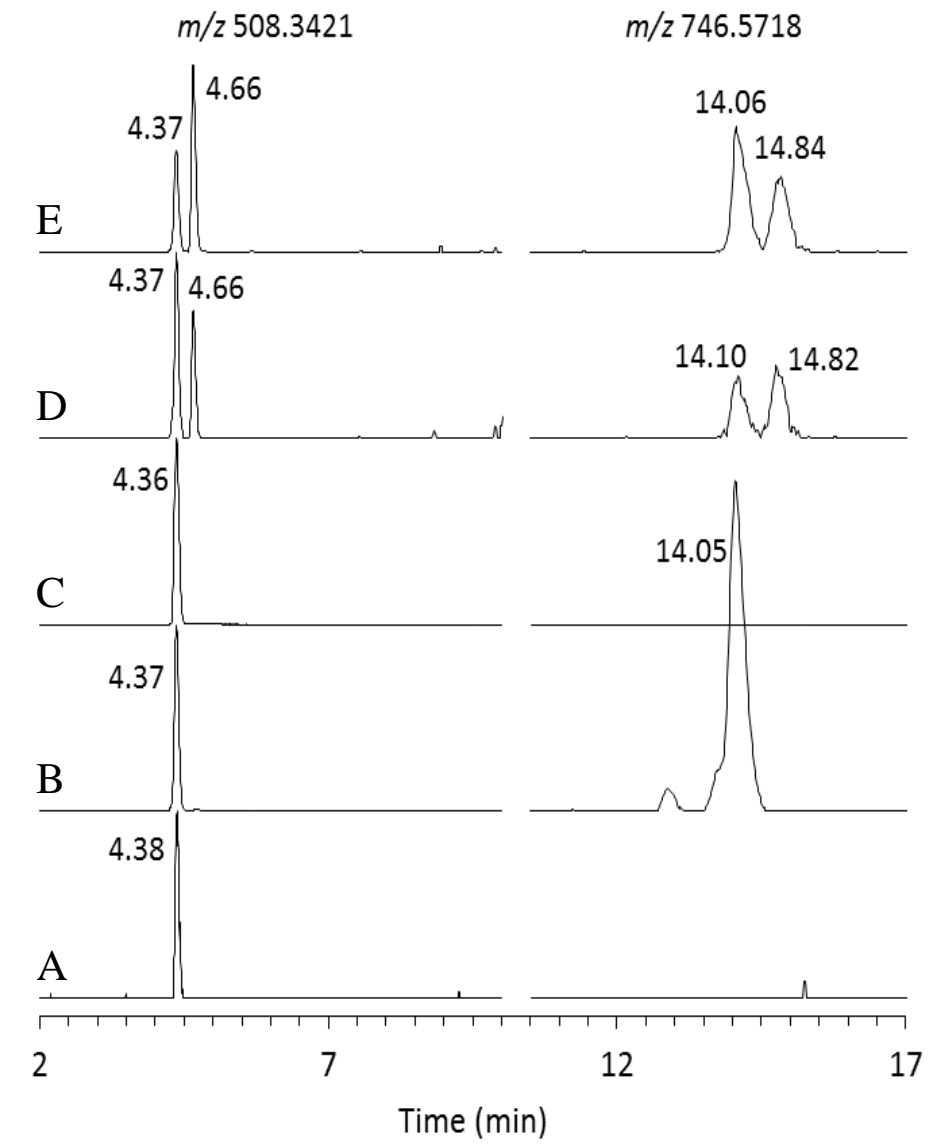

Fig. 3 


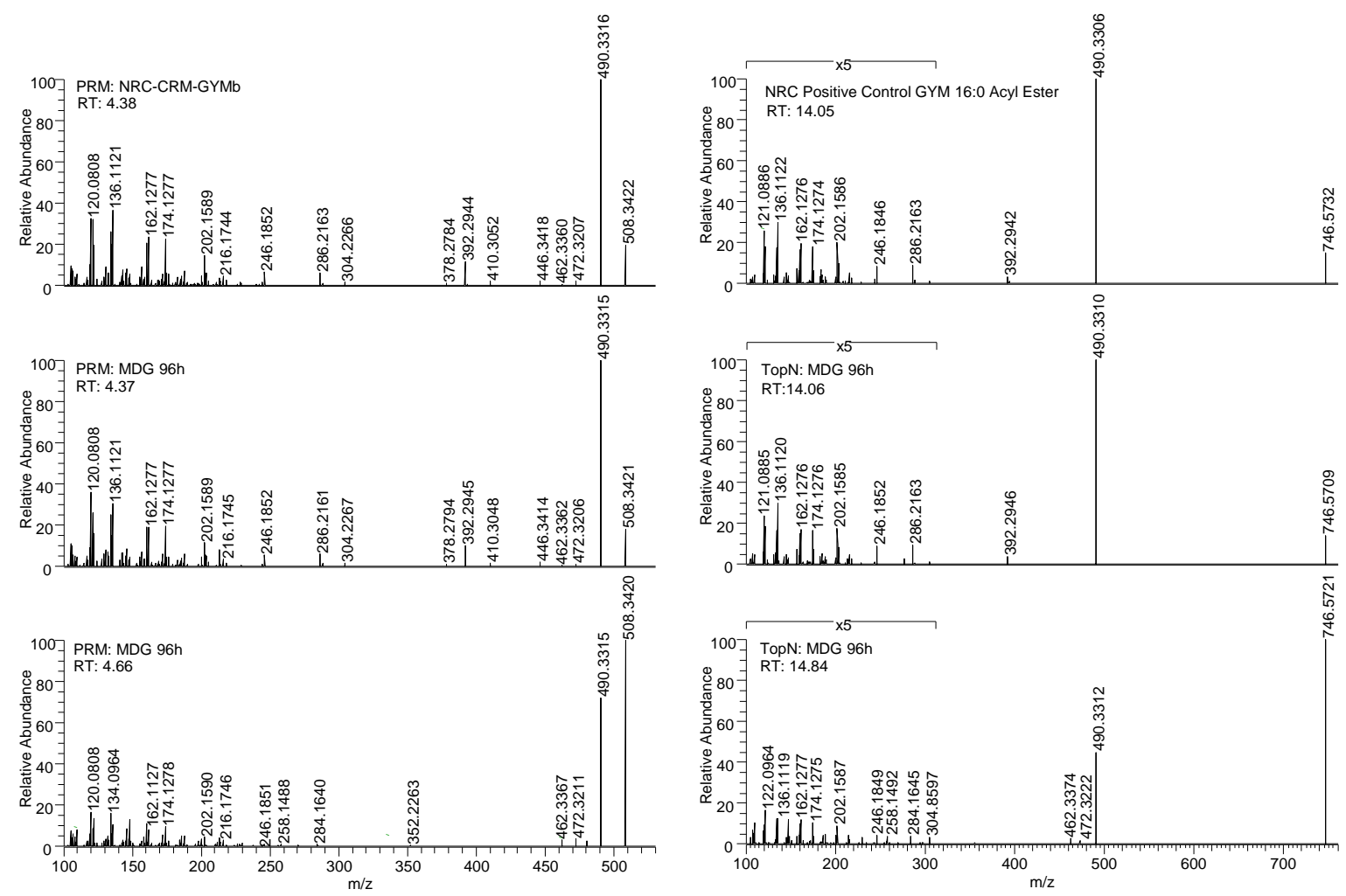

Fig. 4 

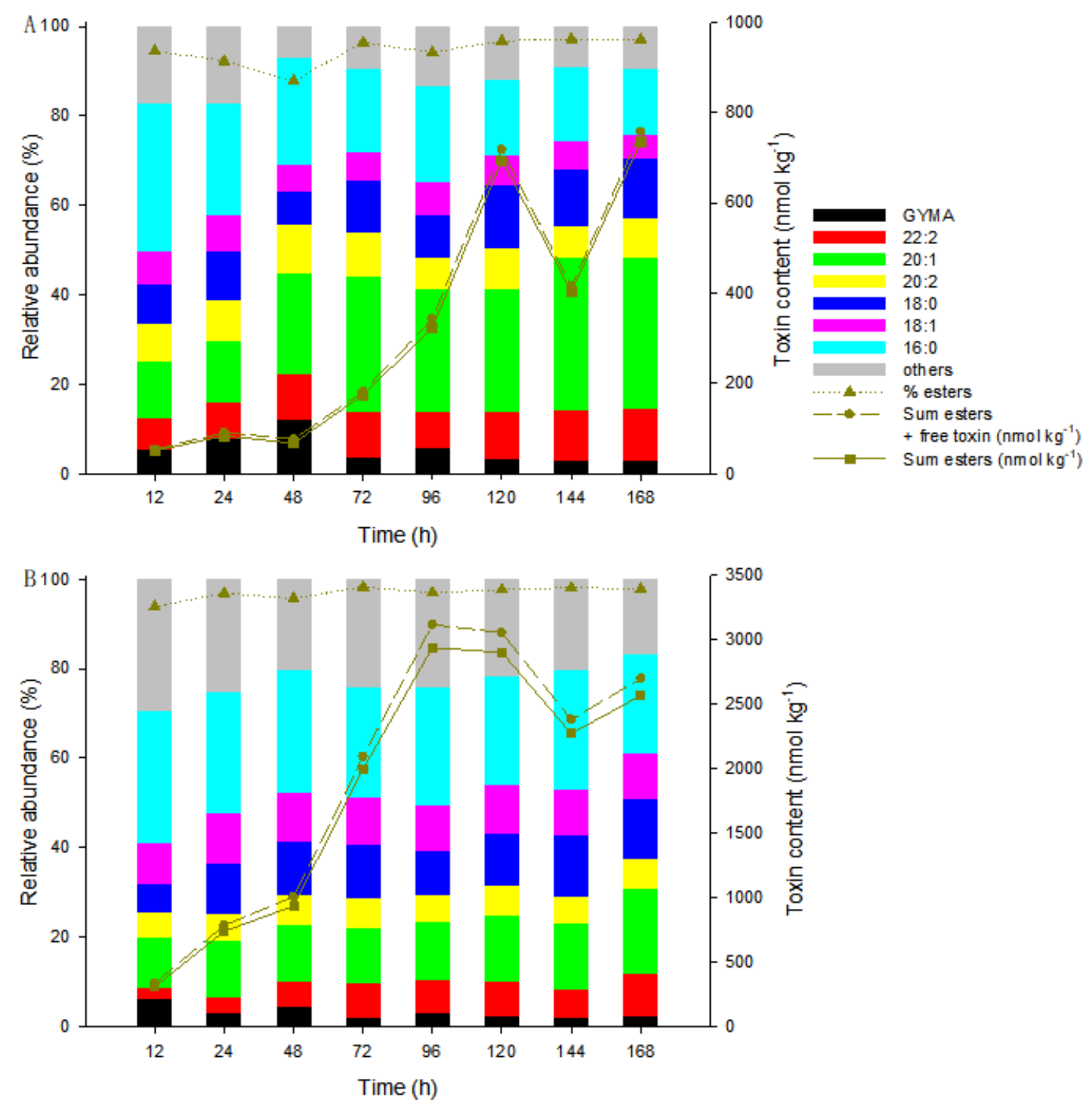

Fig. 5 